\title{
LASER RAMAN AND INFRARED ABSORPTION SPECTRA OF 2,4-DICHLORONITROBENZENE
}

\author{
V.K. RASTOGI, \\ Department of Physics, Lajpat Rai College, Sahibabad-201005 Meerut University, India \\ D.K. JAIN, H.P. MITAL \\ Department of Physics, Meerut College, Meerut-250001, Meerut University, India
}

\section{AND S.N. SHARMA}

Instrumental Analysis Section, Indian Institute of Petroleum, Dehradun-248 005, India

(Received November 7, 1989; in final version September 26, 1990)

\begin{abstract}
The laser Raman and infrared absorption spectra of 2,4-dichloronitrobenzene have been recorded in pure liquid state. The vibrational spectra have been analysed assuming $C_{s}$ point group for the molecule. The assignments for fundamental vibrations, combination and overtone frequencies and internal modes of vibrations of $\mathrm{NO}_{2}$ group have been proposed.
\end{abstract}

PACS numbers: 33.20.Ea, 33.20.Fb, 33.20.Lg

\section{Introduction}

The infrared spectral studies gained an unexpected momentum because of various reasons. A detailed assignment of the fundamental frequencies is useful for the characterisation and identification of the compounds and also for evaluating the force fields and thermodynamic functions of the molecules. The vibrational spectra of monohalogenonitrobenzenes have been studied by several workers [1-14]. Recently the studies on few dihalogenated nitrobenzenes have also been reported [15-16], but so far no work seems to have been done on vibrational spectra of pure liquid 2,4-dichloronitrobenzene. In the present investigation we report the IR and laser Raman spectra of 2,4-dichloronitrobenzene in liquid state. The observed bands have been analysed in terms of fundamentals, combination and difference frequencies. Probable modes of vibrations of the fundamental bands have been assigned. 


\section{Experimental}

The spectrally pure 2,4-dichloronitrobenzene was purchased from $\mathrm{M} / \mathrm{S} \mathrm{Al}-$ drich Chemicals Co, USA in liquid form and was used without further purification. The infrared spectrum was recorded in the region of $200-4600 \mathrm{~cm}^{-1}$ on Nicolet - DX spectrophotometer with thin film specimen. The wavenumber scale was calibrated using the spectrum of a thin sheet of polystyrene. The Raman spectrum $\left(50-3400 \mathrm{~cm}^{-1}\right)$ was excited by the $4880 \AA$ line of an argon ion laser of $100 \mathrm{~mW}$ power and was recorded on Jasco K 500 Raman spectrophotometer. The slit width at the entrance was $380 \mu \mathrm{m}$, the time constant was $0.5 \mathrm{~s}$, and the scanning speed was 5 . Polarization measurements were made by recording the spectra at two perpendicular polarizations. The spectra are shown in Figs. 2-5.

\section{Results and discussion}

Figure 1 shows the structures of nitrobenzene and 2,4-dichloronitrobenzene with classical numbering of the atoms. The present molecule probably belongs to

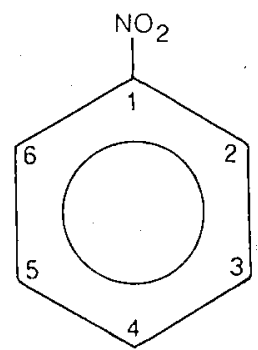

(a)

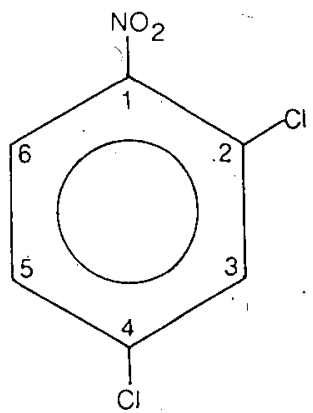

(b)

Fig. 1. Structures of benzene (a) and 2,4-dichloronitrobenzene (b).

the $\mathrm{C}_{s}$ point group as the $\mathrm{NO}_{2}$ group lies in the plane of the benzene ring. The 36 normal vibrations may be classified as $25 \mathrm{a}^{\prime}$ (planar) and $11 \mathrm{a}^{\prime \prime}$ (non-planar) ones. $a^{\prime}$ vibrations are totally symmetric and give rise to polarized Raman lines, whereas $\mathrm{a}^{\prime \prime}$ vibrations are antisymmetric and give rise to depolarized Raman lines. The frequencies of the observed fundamental lines in IR and Raman spectra, their intensities and depolarization factor (in Raman spectrum) and assignments along with vibration numbers in. Wilson's notation of the compound under consideration are given in Table $\mathrm{I}$. The internal vibrations of $\mathrm{NO}_{2}$ group are listed in Table II. The combination and overtone bands for the same compound are listed in Table III. 
Fundamental frequencies $\left(\mathrm{cm}^{-1}\right)$ of 2,4-dichloronitrobenzene

TABLE I

( $\mathrm{s}=$ strong, $\mathrm{vs}=$ very strong, $\mathrm{vvs}=$ very very strong, $\mathrm{m}=$ medium, $\mathrm{w}=$ weak, $\nu=$ stretching, $\beta$ and $\delta=$ in-plane-bending,

$\gamma$ and $\phi=$ out-of-plane bending).

\begin{tabular}{|c|c|c|c|c|c|c|}
\hline & \multirow{2}{*}{$\begin{array}{l}\text { Symm- } \\
\text { etry }\end{array}$} & \multicolumn{2}{|c|}{ Wavenumber } & \multirow{2}{*}{$\begin{array}{l}\text { Dep. } \\
\text { ratio }\end{array}$} & \multirow{2}{*}{$\begin{array}{c}\text { Vib.No. } \\
\vdots\end{array}$} & \multirow{2}{*}{ Assignments } \\
\hline & & $\overline{\mathrm{IR}}$ & Raman & & & \\
\hline 1 & $\mathbf{a}^{\prime}$ & $3107(\mathrm{~s})$ & - & - & 2 & $\nu(\mathrm{C}-\mathrm{H})$ \\
\hline 2 & & - & $3070(\mathrm{vs})$ & 0.54 & $20 \mathrm{a}$ & $\nu(\mathrm{C}-\mathrm{H})$ \\
\hline 3 & & $3018(w)$ & - & - & $7 \mathrm{a}$ & $\nu(\mathrm{C}-\mathrm{H})$ \\
\hline 4 & & $1574(\mathrm{vs})$ & $1565(\mathrm{~s})$ & 0.48 & $8 \mathrm{~b}$ & $\nu(\mathrm{C}-\mathrm{C})$ \\
\hline 5 & & 1542 (vvs) & 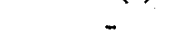 & - & $8 a$ & $\nu(\mathrm{C}-\mathrm{C})$ \\
\hline 6 & & $1468(\mathrm{vs})$ & $1462(w)$ & 0.39 & $19 \mathrm{~b}$ & $\nu(\mathrm{C}-\mathrm{C})$ \\
\hline 7 & & $1427(\mathrm{~m})$ & - & - & $19 \mathrm{a}$ & $\nu(\mathrm{C}-\mathrm{C})$ \\
\hline 8 & & $1311(\mathrm{~m})$ & - & - & 3 & $\beta(\mathrm{C}-\mathrm{II})$ \\
\hline 9 & & $1267(\mathrm{w})$ & - & - & 14 & $\nu$ (C-C) Kekule Vib. \\
\hline 10 & & $1159(\mathbf{s})$ & - & - & 13 & $\beta\left(\mathrm{C}-\mathrm{NO}_{2}\right)$ \\
\hline 11 & & 1134 (vs) & 1132 (vs) & 0.19 & 15 & $\beta(\mathrm{C}-\mathrm{H})$ \\
\hline 12 & & $1100(\mathrm{~s})$ & $1105(\mathrm{w})$ & 0.31 & $18 \mathrm{~b}$ & $\beta(\mathrm{C}-\mathrm{H})$ \\
\hline 13 & & $1025(\mathrm{vw})$ & $1035(\mathrm{~m})$ & 0.28 & 12 & $\delta(\mathrm{C}-\mathrm{C}-\mathrm{C})$ \\
\hline 14 & & $865(\mathrm{vs})$ & $860(\mathrm{~s})$ & 0.20 & 1 & $\nu(\mathrm{C}-\mathrm{C})$ ring breath \\
\hline 15 & & $591(\mathrm{~m})$ & - & - & $6 \mathrm{~b}$ & $\delta(\mathrm{C}-\mathrm{C}-\mathrm{C})$ \\
\hline 16 & & $444(w)$ & - & - & $20 \mathrm{~b}$ & $\nu(\mathrm{C}-\mathrm{Cl})$ \\
\hline 17 & & $430(w)$ & $428(w)$ & 0.31 & $7 \mathrm{~b}$ & $\nu(\mathrm{C}-\mathrm{Cl})$ \\
\hline 18 & & $415(w)$ & $410(\mathrm{~m})$ & 0.31 & $6 \mathrm{a}$ & $\delta(\mathrm{C}-\mathrm{C}-\mathrm{C})$ \\
\hline 19 & & $360(w)$ & - & - & $9 \mathrm{~b}$ & $\beta\left(\mathrm{C}-\mathrm{NO}_{2}\right)$ \\
\hline 20 & & $338(w)$ & - & - & $9 \mathbf{a}$ & $\beta(\mathrm{C}-\mathrm{Cl})$ \\
\hline 21 & & $310(v w)$ & $305(\mathrm{~m})$ & 0.26 & $18 \mathrm{a}$ & $\beta(\mathrm{C}-\mathrm{Cl})$ \\
\hline 22 & $\mathrm{a}^{\prime \prime}$ & 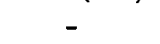 & - & - & 5 & $\gamma(\mathrm{C}-\mathrm{CH})$ \\
\hline 23 & & $800(\mathrm{~s})$ & - & - & $17 \mathrm{~b}$ & $\gamma(\mathrm{C}-\mathrm{H})$ \\
\hline 24 & & 751 (vs) & - & - & 11 & $\gamma(\mathrm{C}-\mathrm{H})$ \\
\hline 25 & & $675(\mathrm{~m})$ & $665(\mathrm{~m})$ & - & 4 & $\phi(\mathrm{C}-\mathrm{C}-\mathrm{C})$ \\
\hline 26 & & $387(w)$ & - & - & $16 \mathrm{a}$ & $\phi(\mathrm{C}-\mathrm{C}-\mathrm{C})$ \\
\hline 27 & & $302(\mathrm{~m})$ & - & - & $16 \mathrm{~b}$ & $\phi(\mathrm{C}-\mathrm{C}-\mathrm{C})$ \\
\hline 28 & & $284(\mathrm{~m})$ & - & - & $10 \mathrm{a}$ & $\gamma\left(\mathrm{C}-\mathrm{NO}_{2}\right)$ \\
\hline 29 & & $253(\mathrm{~s})$ & $250(w)$ & 0.71 & $10 \mathrm{~b}$ & $\gamma(\mathrm{C}-\mathrm{Cl})$ \\
\hline 30 & & - & 198(m) & 0.71 & $17 \mathrm{a}$ & $\gamma(\mathrm{C}-\mathrm{Cl})$ \\
\hline
\end{tabular}




\section{TABLE II}

Internal modes of vibration of the $\mathrm{NO}_{2}$ group in 2,4-dichloronitrobenzene.

\begin{tabular}{l|c|c|l}
\hline & IR & Raman & \\
\hline$\nu_{1}$ & $1525(\mathrm{vvs})$ & $1525(\mathrm{w})$ & $\nu_{\text {asym }}\left(\mathrm{NO}_{2}\right)$ \\
$\nu_{2}$ & $1350(\mathrm{vs})$ & $1340(\mathrm{vvs})$ & $\nu_{\text {sym }}\left(\mathrm{NO}_{2}\right)$ \\
$\nu_{3}$ & $836(\mathrm{vs})$ & - & $\nu_{\mathrm{s}}\left(\mathrm{NO}_{2}\right)$ scissoring \\
$\nu_{4}$ & $547(\mathrm{~s})$ & - & $\nu_{\mathrm{s}}\left(\mathrm{NO}_{2}\right)$ rocking \\
$\nu_{5}$ & $693(\mathrm{w})$ & - & $\nu_{\text {asym }}\left(\mathrm{NO}_{2}\right)$ wagging
\end{tabular}

\section{TABLE III}

\begin{tabular}{l} 
Combination and overtone frequencies $(\mathrm{cm})^{-1}$ \\
\hline $226=1574-1350=224\left(\mathrm{~A}^{\prime}\right)$ \\
$272=1134-865=269\left(\mathrm{~A}^{\prime}\right)$ \\
$298=1134-836=298\left(\mathrm{~A}^{\prime}\right)$ \\
$1676=2 \times 836=1672\left(\mathrm{~A}^{\prime}\right)$ \\
$1711=1159+547=1706\left(\mathrm{~A}^{\prime}\right)$ \\
$1729=2 \times 865=1730\left(\mathrm{~A}^{\prime}\right)$ \\
$1747=1159+591=1750\left(\mathrm{~A}^{\prime}\right)$ \\
$1760=1468+284=1752\left(\mathrm{~A}^{\prime \prime}\right)$ \\
$1808=1525+284=1809\left(\mathrm{~A}^{\prime \prime}\right)$ \\
$1826=1574+253=1827\left(\mathrm{~A}^{\prime \prime}\right)$ \\
$1867=1574+284=1858\left(\mathrm{~A}^{\prime \prime}\right)$ \\
$1913=1159+751=1910\left(\mathrm{~A}^{\prime \prime}\right)$ \\
$1953=1159+800=1959\left(\mathrm{~A}^{\prime \prime}\right)$ \\
$2337=1525+800=2325\left(\mathrm{~A}^{\prime \prime}\right)$ \\
$2520=1427+1100=2527\left(\mathrm{~A}^{\prime}\right)$ \\
$2671=1574+1100=2674\left(\mathrm{~A}^{\prime}\right)$ \\
$2773=1468+1311=2779\left(\mathrm{~A}^{\prime}\right)$ \\
$2858=3107-253=2854\left(\mathrm{~A}^{\prime \prime}\right)$ \\
$2929=1574+1350=2924\left(\mathrm{~A}^{\prime}\right)$ \\
$3155=2 \times 1574=3148\left(\mathrm{~A}^{\prime}\right)$ \\
$3782=3107+675=3782\left(\mathrm{~A}^{\prime \prime}\right)$ \\
$3897=3107+800=3907\left(\mathrm{~A}^{\prime \prime}\right)$
\end{tabular}

Assignments for the observed frequencies have been made on the basis of intensity of IR bands and the nature of polarization of Raman bands.

\subsection{Ring vibrations}

In substituted benzenes, four bands are usually observed in the region of $1400-1650 \mathrm{~cm}^{-1}$. These bands arise from the degenerate $\mathrm{e}_{2 \mathrm{~g}}\left(1595 \mathrm{~cm}^{-1}\right)$ and the $\mathrm{e}_{1 \mathrm{u}}\left(1485 \mathrm{~cm}^{-1}\right) \mathrm{C}-\mathrm{C}$ stretching vibrations of benzene, i.e. vibrations 8 and 19 , according to Wilson's notation, respectively. The fundamental bands $\nu_{4}-\nu_{7}$ observed 
at $1574,1542,1468$ and $1427 \mathrm{~cm}^{-1}$ in the IR spectrum of the present molecule have been assigned to these modes. In the Raman spectrum two polarized bands

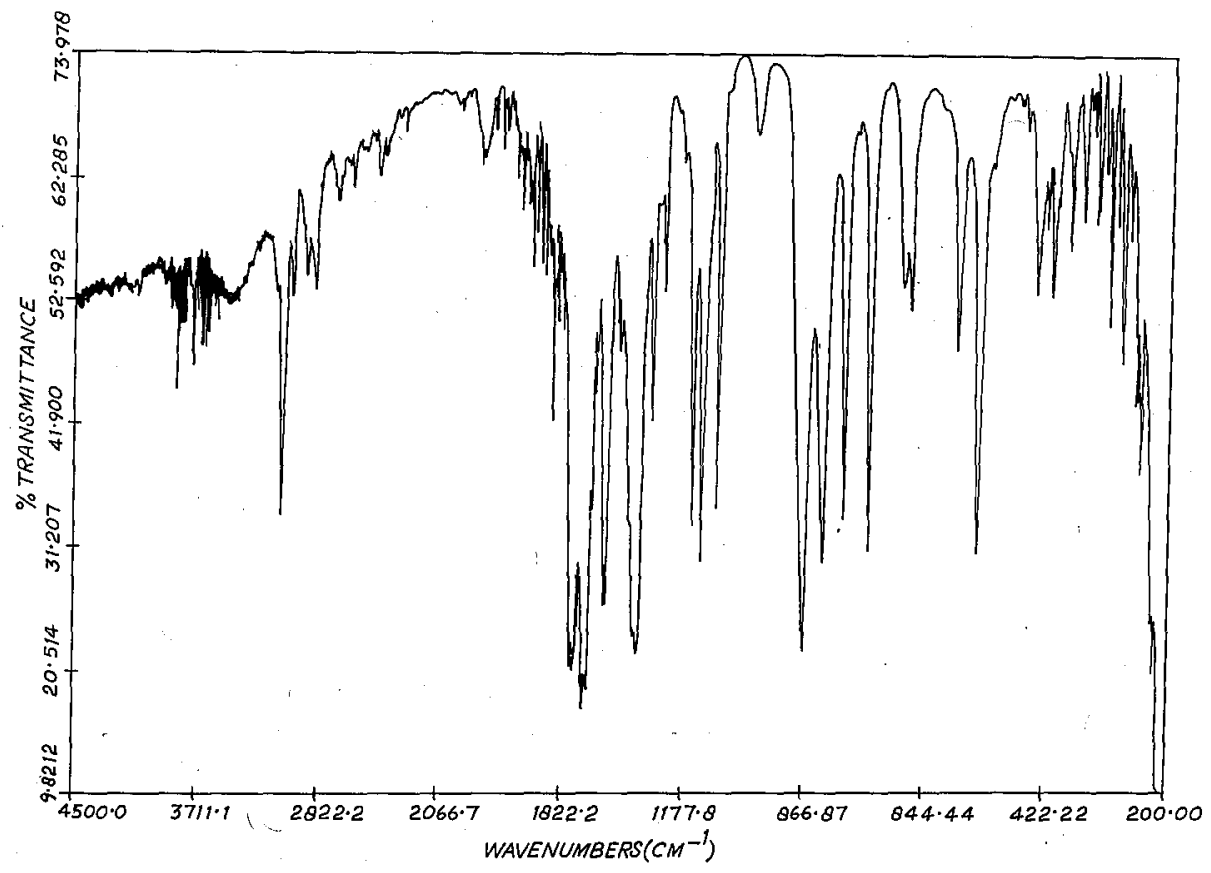

Fig. 2. Infrared spectra of 2.4-dichloronitrobenzene.

at 1565 and $1462 \mathrm{~cm}^{-1}$ could be identified as $\mathrm{C}-\mathrm{C}$ stretching vibrations $\nu_{4}$ and $\nu_{6}$. The C-C vibration 14, $b_{2 u}\left(1310 \mathrm{~cm}^{-1}\right)$, known as the Kekule mode, occurs in the region of $1240-1290 \mathrm{~cm}^{-1}$ in asymmetric vicinal trisubstituted benzenes [17]. This mode has been identified at $1267 \mathrm{~cm}^{-1}$ in the present molecule. The frequency of the ring breathing vibration $1, a_{1 \mathrm{~g}}\left(992 \mathrm{~cm}^{-1}\right)$ of benzene is quite reduced in the $C_{s}$ symmetry due to the interaction with the closely lying $b_{1 u}\left(1010 \mathrm{~cm}^{-1}\right)$ vibration of benzene, since under $C_{s}$ symmetry both these vibrations belong to the same symmetry type, $a^{\prime}$. In the present case the ring breathing vibration has been identified at $865 \mathrm{~cm}^{-1}$ in the IR spectrum. Corresponding to this mode of vibration a strong and polarized band at $860 \mathrm{~cm}^{-1}$ has been observed in the Raman spectrum.

There are three modes associated with ring in-plane deformations which correspond to vibrations $12, \mathrm{~b}_{1 \mathrm{u}}\left(1010 \mathrm{~cm}^{-1}\right)$ and $6, \mathrm{e}_{2 \mathrm{~g}}\left(608 \mathrm{~cm}^{-1}\right)$ of benzene. The observed bands $\nu_{15}$ and $\nu_{18}$ have been assigned as corresponding to $\mathrm{e}_{2 \mathrm{~g}}\left(608 \mathrm{~cm}^{-1}\right)$ mode of benzene. The third in-plane bending vibration is thought to remain virtually undisplaced at nearly $1010 \mathrm{~cm}^{-1}$ and has been observed at $1025 \mathrm{~cm}^{-1}$ in the IR spectrum. Corresponding to these vibrations only two bands at 410 and $1035 \mathrm{~cm}^{-1}$ could be observed in the Raman spectrum and have been assigned 


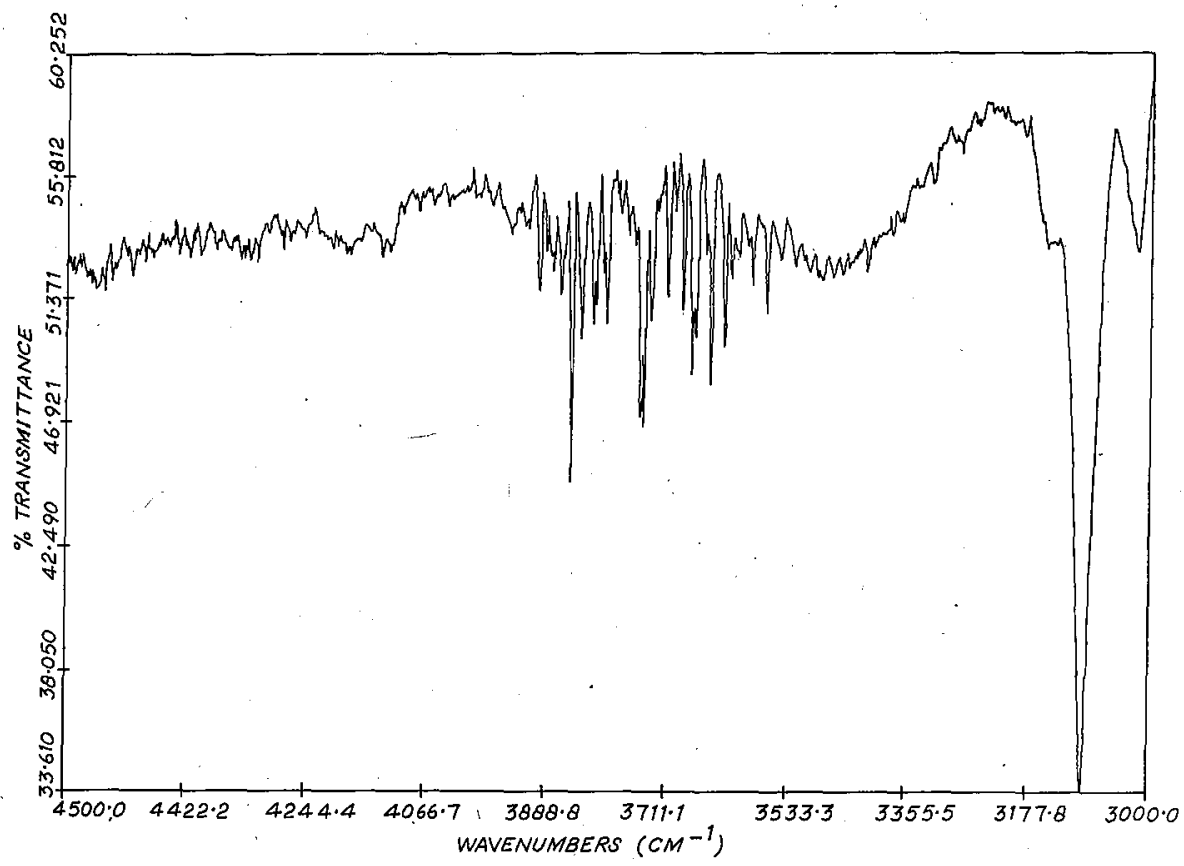

Fig. 3. Infrared spectra of 2.4-dichloronitrobenzene.

to the modes $6 \mathrm{a}$ and 12 , respectively, of benzene. The ring out-of-plane bending vibrations in substituted benzenes owe their origin to the non-degenerate $4, b_{2 g}$ $\left(703 \mathrm{~cm}^{-1}\right)$ and the degenerate $16, \mathrm{e}_{2 \mathrm{u}}\left(404 \mathrm{~cm}^{-1}\right)$ modes of benzene. The IR bands $\nu_{25}, \nu_{26}$ and $\nu_{27}$ in the present molecule have been assigned to these three $\mathrm{C}-\mathrm{C}$ out-of-plane bending vibrations. In the Raman spectrum only the non-degenerate mode 4 could be observed at $665 \mathrm{~cm}^{-1}$.

\section{2. $C-H$ and $C-X$ vibrations}

The $\mathrm{C}-\mathrm{H}$ stretching frequencies in benzene derivatives arise from two non-degenerate $a_{1 \mathrm{~g}}\left(3073 \mathrm{~cm}^{-1}\right)$ and $b_{1 \mathrm{u}}\left(3060 \mathrm{~cm}^{-1}\right)$ and two degenerate modes $\mathrm{e}_{2 \mathrm{~g}}\left(3046 \mathrm{~cm}^{-1}\right)$ and $\mathrm{e}_{1 \mathrm{u}}\left(3080 \mathrm{~cm}^{-1}\right)$, i.e. vibrations $2,13,7$ and 20 , respectively. In trisubstituted benzenes, three of these modes would give rise to three C-II stretching frequencies which almost retain the frequencies of benzene and lie in the region of $3000-3100 \mathrm{~cm}^{-1}$, while the other three frequencies would depend on the mass and nature of substituents and decrease considerably below $1200 \mathrm{~cm}^{-1}$ [18]. In the present investigation only two bands at 3107 and $3018 \mathrm{~cm}^{-1}$ could be observed due to $\mathrm{C}-\mathrm{H}$ stretching vibrations in the IR spectrum, whereas in the Raman spectrum. only one band was observed at $3070 \mathrm{~cm}^{-1}$. The substituent sensitive stretching vibrations have been identified at 1159,444 and $430 \mathrm{~cm}^{-1}$ in 


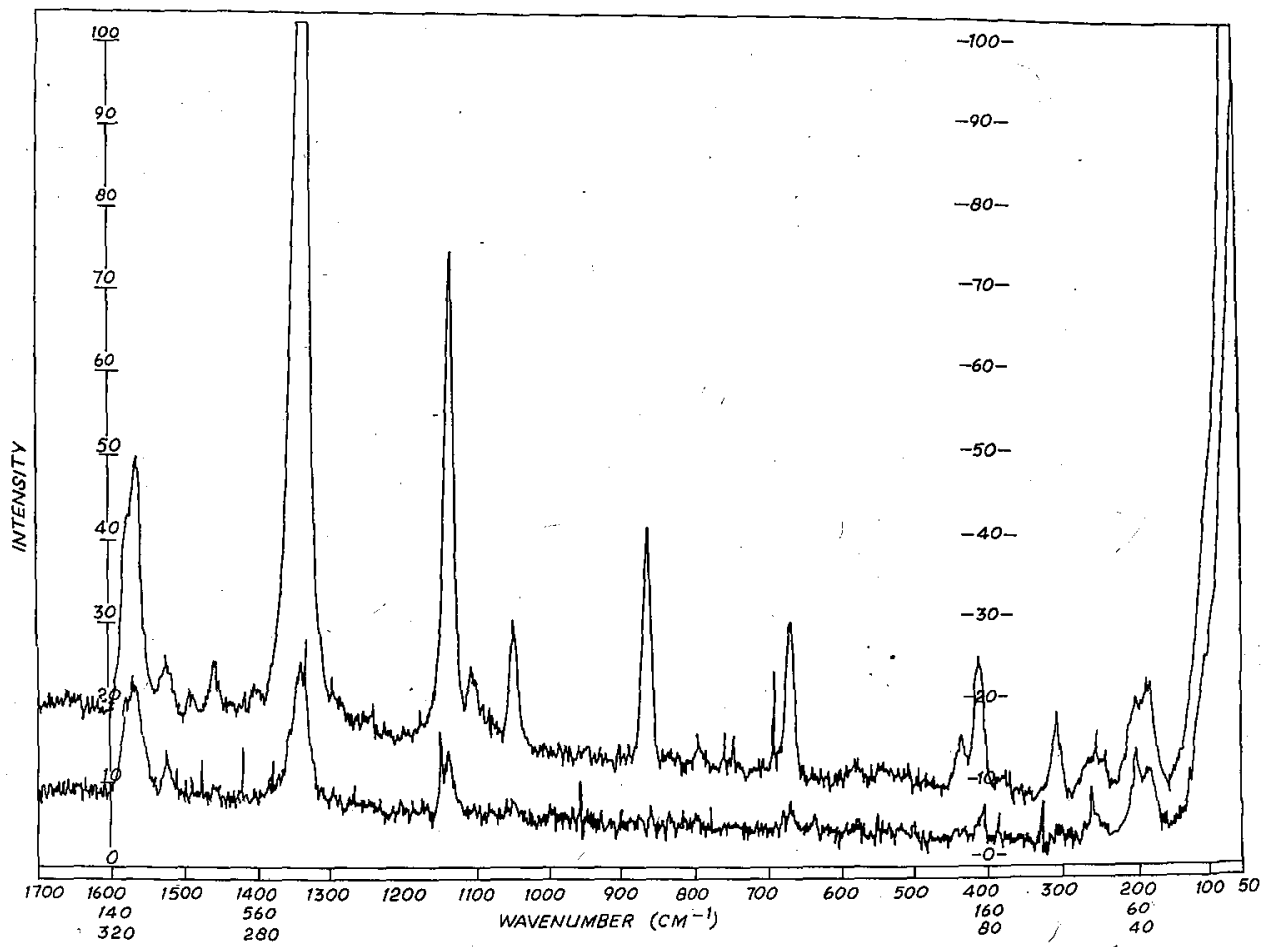

Fig. 4. Raman spectra of 2,4-dichloronitrobenzene.

the IR spectrum, whereas in the Raman spectrum only one of these vibrations has been observed at $428 \mathrm{~cm}^{21}$.

There are two degenerate $\mathrm{e}_{2 \mathrm{~g}}\left(1178 \mathrm{~cm}^{-1}\right)$ and $\mathrm{e}_{1 \mathrm{u}}\left(1033 \mathrm{~cm}^{-1}\right)$ and two non-degenerate $b_{2 u}\left(1150 \mathrm{~cm}^{-1}\right)$ and $\mathrm{a}_{2 \mathrm{~g}}\left(1326 \mathrm{~cm}^{-1}\right)$ modes of vibrations, i.e. vibrations $9,18,15$ and 3 in benzene, which involve $\mathrm{C}-\mathrm{H}$ in-plane bending vibrations. In trisubstituted benzenes, these modes should give rise to three planar bending vibrations involving the substituents and three involving the three hydrogen atoms. In asymmetric trisubstitution, the normal modes 3,15 and $18 \mathrm{~b}$ are regarded as $\mathrm{C}-\mathrm{H}$ in-plane bending vibrations and the normal modes $9 \mathrm{a}, 9 \mathrm{~b}$ and 18a are regarded as $\mathrm{C}-\mathrm{X}$ in-plane bending vibrations. [17]. In the present molecule the observed fundamental frequencies $\nu_{8}, \nu_{11}^{\prime}, \nu_{12}$ in the IR/Raman spectra have been assigned to $\mathrm{C}-\mathrm{H}$ in-plane bending vibrations and $\nu_{19}, \nu_{20}$ and $\nu_{21}$ to the $\mathrm{C}-\mathrm{X}$ in-plane bending vibrations. 


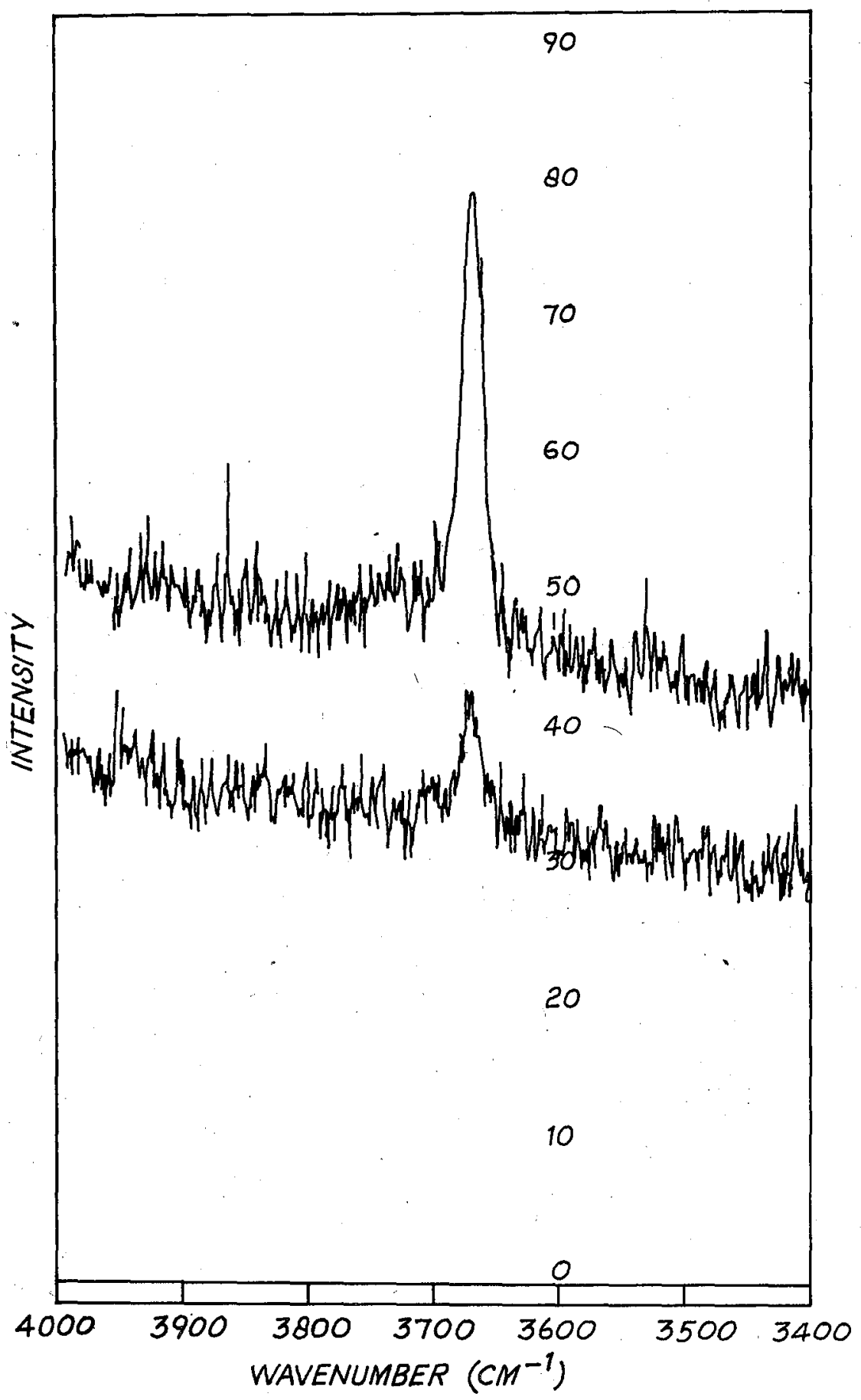

Fig. 5. Raman spectra of 2,4-dichloronitrobenzene. 
The three $\gamma(\mathrm{C}-\mathrm{H})$ and three $\gamma(\mathrm{C}-\mathrm{X})$ modes of vibrations of trisubstituted derivatives are derived from the six $(\mathrm{C}-\mathrm{H})$ modes of benzene. The vibrational modes $5,17 \mathrm{~b}$ and 11 for compound under consideration correspond to (C-H) and the remaining three modes $17 \mathrm{a}, 10 \mathrm{a}$ and $10 \mathrm{~b}$ correspond to (C-X) [17]. The IR frequencies $\nu_{22}, \nu_{23}$ and $\nu_{24}$ have been identified as $\gamma(\mathrm{C}-\mathrm{H})$ corresponding to the modes $5,17 \mathrm{~b}$ and 11, respectively. Frequencies below $350 \mathrm{~cm}^{-1}$ are to be assigned as $\gamma(\mathrm{C}-\mathrm{X})$. The IR/Raman frequencies $\nu_{28}, \nu_{29}$ and $\nu_{30}$ have been assigned as the three $\mathrm{C}-\mathrm{X}$ out-of-plane bending vibrations $10 \mathrm{a}, 10 \mathrm{~b}$ and $17 \mathrm{a}$, respectively.

\subsection{Internal vibrations of $\mathrm{NO}_{2}$ group}

The $\mathrm{NO}_{2}$ group has two stretching frequencies, one being symmetric and the other asymmetric. Randle and Whiffen [19] assigned the symmetric stretching . frequency to a band lying between 1333 and $1370 \mathrm{~cm}^{-1}$ and the antisymmetric frequency between 1494 and $1539 \mathrm{~cm}^{-1}$ in the spectra of aromatic nitrobenzene derivatives. In the present case we have assigned the strong bands at 1355 and $1525 \mathrm{~cm}^{-1}$ (Table II) to $\mathrm{NO}_{2}$ symmetric and asymmetric stretching vibrations, respectively, in accordance with the assignments made by Mooney [7], Kishore et al. [20] and Singh and Rai [21]. In the Raman spectrum the symmetric vibration has appeared very strongly at $1340 \mathrm{~cm}^{-1}$ but asymmetric vibration has occurred weakly at $1525 \mathrm{~cm}^{-1}$. The bands observed at 836,693 and $547 \mathrm{~cm}^{-1}$ in the IR spectrum have been assigned to $\mathrm{NO}_{2}$ scissoring, wagging and rocking vibrations, respectively. These assignments find support from the work of Varsanyi et al. [22], Green and Harison [11] and Ahmad and Verma [8]. The band at $180 \mathrm{~cm}^{-1}$ in the Raman spectrum may be the first overtone of $\mathrm{NO}_{2}$ torsion.

\subsection{Combination and overtone bands}

The moderately strong and weak bands at frequencies that could not be reasonably assigned to fundamentals, may be combinations and overtones of normal modes, whose assignments have been made in Table III according to the direct product rule for the point group $C_{s}$ :

\section{Acknowledgments}

The authors are thankful to Prof. G. Botura, Departimento di Biochimica, University of Bologna for allowing us to record laser Raman spectra. The authors are also thankful to Mr. S.C. Tyagi, for providing necessary literature in the College Library. One of the authors (H.P.M.) thanks UGC, New Delhi for the award of financial assistance.

\section{References}

[1] H. Wittek, Z. Phys. Chem., Leipz. B 52, 315 (1942). 
[2] Gariggon C. Lagrange, J.M. Lebas, M.L. Josien, Spectrochim. Acta 12, 305 (1958).

[3] E.F. Mooney, Spectrochim. Acta 19, 877 (1963).

[4] E.F. Mooney, Spectrochim. Acta 20, 1021 (1964).

[5] V.B. Singh, R.N. Singh, I.S. Singh, Spectrochim. Acta 22, 927 (1966).

[6] V.S. Griffiths, H.W. Thompson, Proc. R. Soc. Edinb. A, Math. 298, 51 (1967).

[7] K.C. Medhi, Spectrochim. Acta 20, 675 (1964).

[8] S. Ahmad, P.K. Verma, Indian J. Phys. B 62, 509 (1988).

[9] I. Colthup, J. Opt. Soc. Am. 30, 397 (1950).

[10] D.H. Whiffen, J. Chem. Soc. Faraday Trans. 1350.(1956).

[11] J.H.S. Green, Spectrochim Acta A 26, 1503 (1970).

[12] B.B. Lal, M.D. Srivastav, I.S. Singh, Indian J.. Pure Appl. Phys. 11, 615 (1973).

[13] R.N. Singh, S.C. Prasad, Spectrochim: Acta A 34, 39 (1978).

[14] P. Pommez, M. Lafaiz, P. Delorme, V. Lorenzelli, J. Chim. Phys. 64, 1450 (1967).

[15] S.K. Singh, R.N. Singh, Indian J. Pure Appl. Phys. 22, 112 (1984).

[16] R.P. Singh, R.N. Singh, Indian J. Phys. B 62, 502 (1988).

[17] G. Varsanyi, Vibrational spectra of benzene derivatives, Academic Press, New York 1969.

[18] R.R. Randle, D.H. Whiffen, Molecular spectroscopy, Institute of Petroleum, London 1956.

[19] R.R. Randle, D.H. Whiffen, J. Chem. Soc. Faraday Trans. 4153 (1952).

[20] Y. Kishore, S.N. Sharma, C.P.D. Dwivedi, Indian J. Phys. 48, 412 (1974).

[21] R.B. Singh, D.K. Rai, Indian J. Phys. B 60, 404 (1986).

[22] G. Varsanyi, S. Holly, L. Imre, Spectrochim. Acta A 23, 1205 (1967). 